\title{
Article
}

\section{Challenges to and facilitators of occupational epidemiology research in the UK}

Sweity, Samaher, Sutton, Chris, Downe, Soo, Balaam, Marie-Clare and McElvenny, Damien M.

Available at http://clok.uclan.ac.uk/33530/

Sweity, Samaher, Sutton, Chris, Downe, Soo ORCID: 0000-0003-2848-2550, Balaam, Marie-Clare ORCID: 0000-0003-4511-7352 and McElvenny, Damien M. (2020) Challenges to and facilitators of occupational epidemiology research in the UK. Health Policy, 124 (7). pp. 772-780. ISSN 0168-8510

It is advisable to refer to the publisher's version if you intend to cite from the work. http://dx.doi.org/10.1016/j.healthpol.2020.05.006

For more information about UCLan's research in this area go to http://www.uclan.ac.uk/researchgroups/ and search for <name of research Group>.

For information about Research generally at UCLan please go to http://www.uclan.ac.uk/research/

All outputs in CLoK are protected by Intellectual Property Rights law, including Copyright law. Copyright, IPR and Moral Rights for the works on this site are retained by the individual authors and/or other copyright owners. Terms and conditions for use of this material are defined in the policies page.

\section{CLoK}

Central Lancashire online Knowledge www.clok.uclan.ac.uk

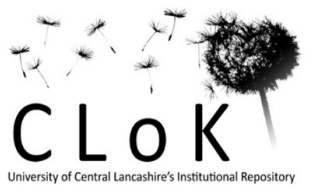




\title{
Challenges to and Facilitators of Occupational Epidemiology Research in the UK
}

\begin{abstract}
This study investigated the challenges and facilitators of occupational epidemiology (OE) research in the UK, and evaluated the impact of these challenges. Semi-structured in-depth interviews with leading UK-based OE researchers, and a survey of UK-based OE researchers were conducted. Seven leading researchers were interviewed, and there were 54 survey respondents. Key reported challenges for $\mathrm{OE}$ were diminishing resources during recent decades, influenced by social, economic and political drivers, and changing fashions in research policy. Consequently, the community is getting smaller and less influential. These challenges may have negatively affected OE research, causing it to fail to keep pace with recent methodological development and impacting its output of high-quality research. Better communication with, and support from other researchers and relevant policy and funding stakeholders was identified as the main facilitators to OE research. Many diseases were initially discovered in workplaces, as these make exceptionally good study populations to accurately assess exposures. Due to the decline of manufacturing industry, there is a perception that occupational diseases are now a thing of the past. Nevertheless, new occupational exposures remain under-evaluated and the UK has become reliant on overseas epidemiology. This has been exacerbated by the decline in the academic occupational medicine base. Maintaining UK-based OE research is hence necessary for the future development of occupational health services and policies for the UK workforce.
\end{abstract}

Keywords

Occupational Epidemiology; Occupational Health; Occupational Medicine; Challenges and Facilitators; United Kingdom 


\section{Background}

Work-related ill-health and injuries impose social and economic costs on individuals, employers, the community, and the government. In 2016-2017, approximately 1.3 million working people suffered from an illness that was caused or made worse by their work (Health and Safety Executive, 2017). The ill-health of the working population is estimated to cost the UK economy around $£ 100$ billion a year (Black, 2008; Department for Work and Pensions and Department of Health, 2016).

The field of occupational epidemiology (OE) is a branch of occupational health research (Lalloo et al., 2019b). It is an important aid to understanding the impact of work on health; to the development of occupational health services (OHS); and to the formulation of public and occupational health policies (International Labour Office, 2009; Lalloo et al., 2019a; Peckham et al., 2017). It has contributed enormously to the identification of workplace risks, and a large number of workplace improvements have been introduced as a consequence, thus playing a vital role in improving the health of the working population (Checkoway et al., 2004, pp 5-14; Graber et al., 2013, pp. 11-12; Guidotti, 2000; Newill, 1983). The potential for prevention is generally greater than in other epidemiology fields, since occupational hazards can often be easily identified then reduced or eliminated (International Labour Office, 2009; Rushton, 2017). Furthermore, new and potentially future occupational risks are emerging (e.g. nanotechnology) that require further epidemiological investigation. Additionally, the implications of $\mathrm{OE}$ research have a potentially greater impact than other epidemiological fields to improve the environmental and public health (e.g. environmental air pollution) (Dimakakou et al., 2018).

Facilitating OE research is therefore important for a healthy and thriving national economy. However, there is anecdotal evidence to suggest that $\mathrm{OE}$ (and $\mathrm{OH}$ research in general), in the UK, is facing many challenges including; a diminishing workforce, reduced funding, and decreased government and stakeholders' interest in this field (Black, 2008; Faculty of Occupational Medicine, 2006; Lalloo et al., 2019a; Stayner et al., 2017; Vaughan-Jones and Barham, 2009; Wegman, 2014). Given the implications for workforce health, it is important to understand why, despite the clear benefits that OE delivers, it encounters such challenges. A systematic search of the literature revealed limited evidence regarding these issues (e.g. Coggon, 2005; Hotopf and Wessely, 2005; Lalloo et al., 2019a; Lalloo et al., 2019b; Lalloo et al., 2018; Rushton and Betts, 2001). This study hence aimed to identify current challenges and facilitators of $\mathrm{OE}$ research in the $\mathrm{UK}$, and to assess the perceived impact of the challenges. 


\section{Methods}

A mixed-methods approach was employed (Schoonenboom and Johnson, 2017; Tashakkori and Teddlie, 2010) including semi-structured interviews to explore the experiences and perceptions of UK-based leading OE researchers (i.e. professors of OE and/or OE researchgroup leaders), and a survey of UK-based OE researchers based on the themes which emerged from these index interviews.

\section{Semi-structured interviews}

An interview guide was developed based on the study research questions and the existing literature. The main topics covered in the interviews were: the participants' experiences of key challenges and facilitators encountered whilst conducting OE research; whether they were able to address the challenges encountered; how the challenges and facilitators impacted on their studies; whether these challenges were also experienced by other colleagues; and their recommendations on how the difficulties could be addressed.

Purposive sampling was used to identify potential participants. In this sampling technique, individuals with the most knowledge and experience of the phenomenon of interest are identified and selected to allow effective use of limited resources (Patton, 2002, pp. 45-46). Twelve leading researchers were identified by the field expert author (DMM) and invited by email to participate. The plan was to interview as many of those invitees as possible until data saturation was reached. Data saturation is usually achieved when further analysis of the interview data reveals no new themes (Fusch and Ness, 2015). Written informed consent was obtained from those who agreed to participate. Interviews were recorded, transcribed verbatim and anonymised. Data were managed by MAXQDA10 software (https://www.maxqda.com/) and analysed by the lead author (SS) using thematic analysis (Nowell et al., 2017).

\section{Survey Design}

A questionnaire was specifically developed for this phase of the study based on the themes identified in the literature and interviews. The questionnaire items were scrutinised and tested by the study team. It included 26 Likert-style challenges and facilitators statements each with a five-point scale from strongly agree to strongly disagree (see Supplementary material). Likert Scales are commonly used to measure attitude, providing a range of responses to a given question or statement (Cohen et al., 2011, pp. 386-387). The challenges included 17 statements on data/participant access and availability, study design, funding and publication. The facilitators included nine statements on support and interest of relevant stakeholders, appropriate study planning and design, and effective communication. The questionnaire also included nine open-ended questions in relation to the participants' perspectives of the impacts 
of the challenges and strategies employed to overcome such challenges, and six demographic questions that kept identity concealed.

\section{Sample size and setting}

The target population in this survey was the UK-based OE research community. The number of researchers in this field is small, but it was difficult to estimate accurately the exact number. The Faculty of Occupational Medicine (2011) estimated that there were an approximately 27 full-time equivalent academic posts in occupational medicine, not all of whom were active in epidemiological research. This number, however, did not include other academics such as statisticians, exposure scientists and non-medical epidemiologists. In the absence of a suitable sampling frame covering the whole community, a convenience sample was chosen (Etikan, 2016). Potential participants were handed the questionnaires at the International Conference on Epidemiology in Occupational Health conference (EPICOH, Oxford, September 2011). EPICOH is the largest international conference on OE and was held in the UK at the time of this phase of the study. This provided an ideal opportunity to approach a substantial percentage of the UK-based OE researchers. The conference delegate list included 86 UK delegates, all of whom would have an interest in OE. Another 61 potential participants were identified by screening websites of relevant universities' departments, governmental bodies and other institutions (identified from the conference delegate list and online search) and by snowball sampling (i.e. by asking participants to identify other potential participants). Participants were chosen based on their profiles and/or published work. The aim was to include all researchers in the field of OE. Criteria for inclusion dictated that each participant was an active researcher in the field of OE. No restrictions were applied on the type of work or roles of these researchers; hence, various professionals within OE were included, such as statisticians, epidemiologists, and healthcare professionals (e.g. occupational physicians and nurses). Based on the above extensive search, it is likely that there were less than 200 OE researchers in the UK at that time.

The study questionnaire pack included a pre-paid addressed envelope, and a cover letter that explained this phase of the study and provided instructions to post the questionnaire after completion. To improve the response rate among UK-based OE researchers, posters promoting the survey were placed on different advertising boards at the EPICOH conference. Furthermore, a reminder letter along with the questionnaire pack was sent out to all conference participants and potential participants identified by snowball sampling, on two occasions, during a four-week window following their receipt of the original questionnaire pack. The questionnaire was also completely anonymously; therefore, these reminder messages were sent out to all invited participants, including those who had already submitted their responses anonymously. Descriptive statistics were used to summarise the data using SPSS (IBM Corp., 2010). 


\section{Interview results}

\section{Participants}

By the fifth interview no new themes were identified; two more interviews were conducted to confirm data saturation was in fact achieved. The leading researchers were interviewed faceto-face at their workplace with the exception of one, who preferred to be interviewed by telephone. Their OE research experience ranged from 10-30 years. Six of them had medical backgrounds and one had a science background. Their work areas and settings had varied over time; these included the National Health Service (NHS), and government, academic, and industrial settings. Interviews lasted from 30-70 minutes.

\section{Findings}

Thematic analysis of the data revealed two broad themes, 'Challenges of carrying out OE research' and 'Facilitators that contributed to successful OE research', each of which included five sub-themes as detailed next. No new themes or sub-themes were identified from the final two interviews; this suggested that these findings were comprehensive and transferable.

\section{Challenges}

Under the challenges theme, the following sub-themes were identified: lack of resources; difficulties accessing data and participants; workers' records issues; recruitment difficulties; and publication issues. Generally, participants felt that conducting OE studies had become increasingly difficult as these challenges had become more severe over time.

\section{Lack of resources}

Participants reported that $\mathrm{OE}$ lacked funding and expertise, impacting negatively on its research output. The participants' main concern was the lack of specific, targeted funding bodies and opportunities:

'There are few charities that fund occupational health research in the UK, but they do not have a lot of money. Government funding is considered to be constrained and the research council $[\mathrm{MRC}]$ would occasionally fund some work that is relevant to it...' (P5).

'The HSE do not have a lot of money to fund external research...' (P1).

Another issue identified was that the OE community has been getting smaller over time; many key researchers had recently retired, and some of those who remained were near 
retirement. This contributed to a shortage of expertise in specific OE areas and difficulty recruiting younger researchers:

'There are very few academics...So there is a very small community, and that means it is probably below a critical point. There are very few of them left in this country. So [for example] gaining good opinions on exposure measurements is pretty tricky' (P3).

Some of the respondents also reported inadequate support from public, academic, private, and charitable sources, which, they felt, sent negative signals to young researchers planning their careers in this field:

'The cohort of occupational researchers in the UK are rather old.... and there is not a clear career structure for younger folk who want to come into occupational research lines. There's only one lecturer in occupational research in [all over] the UK. There are one or two in sort of peripheral areas who do something in work and health' (P6).

Participants implied that due to lack of human and financial resources, the OE community may have not been able to keep pace with recent methodological developments. This subsequently might have made it even more difficult to attract funding and young researchers to the field, further limiting the number of high quality research produced in this field in a vicious cycle:

'If you can't get good research then you are not going to attract good researchers, and if you do not get good researchers, it becomes a vicious cycle. The UK has done good quality research over the years, but now there are just fewer of us doing it. There are fewer institutions that have got a good core group, and we are old. So, until we can get the younger people coming up [joining the $\mathrm{OE}$ field], that [doing more high-quality research] is going to be difficult to do. We have to do good quality research to make people say "wow, I want to do that", and it is worth doing. '(P6).

Interestingly, some respondents felt that OE was less attractive to stakeholders, such as funding bodies, to invest in because it is viewed as an old-fashioned field, rarely employing innovative methodologies such as molecular and genetic techniques. Some participants believed that, despite the lack of cutting-edge methods, their research was still worth funding and addressed important questions. They, however, acknowledged that using such newer methods would have improved their chances of getting funding:

'A lot of it (OE) uses techniques that most people would find very old-fashioned and that is not attractive to a lot of funding bodies. I have just lost a grant to the MRC despite very good reviews. I think that was because it did not include any cutting-edge technology. I know it should have [included cutting-edge methodology], but for that reason it is not attractive to them, even if you could persuade them there is a big and important problem' (P3).

'I have yet to see in this meeting [EPICOH conference], for instance, anything [referring to OE studies presented during the conference] particularly innovative. It has been interesting, 
but I have seen nothing made me step back and say "wow that is a real step forward", in terms of methodology. It is all a variation on a theme really, and that is where we need to go [incorporate and use innovative methodologies]. ' (p6)

Another reason mentioned for lack of interest in this field was that the National Institute for Health Research (NIHR), a key government funding organisation for health research, primarily funds research directed towards the benefit of patients in the NHS. However, in most of OE, the target populations are typically healthy workers or employees (e.g. NHS workforce, factory workers) and not patients:

'...the NIHR has few funding opportunities for $\mathrm{OH}$ [including $\mathrm{OE}$ ], and that it is pretty much for patient benefits. They do not see staff as patients, whereas the NHS staff are our patients, but the NIHR won't fund these studies.' (P7).

To make OE more attractive to funding bodies and researchers, some participants suggested incorporating innovative methodologies and establishing a wider network including those who have more knowledge and skills in these techniques:

'The epidemiologists need to talk more with the mechanistic people, understanding the mechanism of disease, and ...the effects of work on health... involving social scientists, labour economists, health economists. These sorts of people have been peripherally, if at all, involved in occupational research. They should start becoming more involved: that is the only way forward. I think over the next 5-10 years we will be seeing more and more work where you can link in the new molecular stuff, molecular epidemiology, particularly using human genome technology, and I think then $O E$ will be able to take another step forward' (P6).

Difficulties accessing data and participants

All respondents experienced some level of difficulty accessing data and participants. The level of difficulty was perceived to be primarily dependant on the types of studies and settings where these studies were conducted:

'The studies in the early days, in 1970's and 1980's, were easiest to set up. Because, then, getting permissions was straightforward, and of course it has become increasingly a bureaucratic nightmare to do anything useful [nowadays]' (P4).

Obtaining approval from industry management or employers was perceived to be the most challenging, because studies cannot be conducted if managers/employers object, and it can also take a long time to persuade them to agree:

'...getting access to populations ...can take years. Two main difficulties [funding and access] we have; one is getting buy-in from industry. At the moment I am very interested in working with the $X$ [a specific industry], because there is a big problem with $Y$ [a health condition] 
there. But trying to persuade the industry that this is something needs to be looked at is very difficult, and they are not at all enthusiastic [about allowing this study to happen]' (P3).

Another concern was gaining ethical and other research governance approvals, but this was seen to be less problematic than obtaining funding and industry clearance:

'Nowadays [gaining approvals] is much more onerous, and the driving force is the autonomy of the individual subject, and a belief that only with the consent of an individual one can have access to their data, which is a big challenge.' (P2).

\section{Workers' records issues}

The accuracy, completeness, accessibility and availability of the workforce records were other hurdles identified by the interview phase participants. The issues included missing data, inappropriate storage of records, and unavailability or destruction of records:

'Sometimes there are technical reasons why one might not go ahead with research that would be valuable to do. And this is due to local factors such as the failure to retain the appropriate records' (P2).

Apart from early destruction and unavailability of records, the interview participants appeared to expect these kinds of hurdles in OE studies, and believed that incomplete or missing data in some fields within the records are minor technical problems that are always experienced in $\mathrm{OE}$ and can mostly be addressed:

'That is very variable [records issues]; sometimes they are a complete mess. But I do not see that as a problem, I see that as a technical thing you have to overcome. I do not see that as a barrier, it is just part of the game really in $O E$ is to try and get the exposure assessments, and health records' (P3).

\section{Recruitment difficulties}

A declining response rate in OE surveys and case-control studies was perceived as another major hurdle:

'We have problems with lower response rates now than we used to get, and this has been a trend over time... Historically, I have done studies, where I had response rates of $80 \%$ and now you might get $50 \%$ or something like that' (P1).

Some respondents also highlighted certain legal and compensation issues that might affect participants' involvement in a study:

'During one of our studies, it was not the workforce was refusing to take part; they just were not being honest [during interviews for the purpose of collecting information for one 
particular OE study], because they thought it might affect their eligibility for compensation. So, we had to abandon the study' (P1).

Publication issues

Participants reported difficulties in publishing OE research in high impact journals, especially if study findings were initially disseminated to the workforce. Participants also thought that the editors of the high impact journals do not see OE studies as exciting, because these studies rarely use cutting-edge methodologies such as molecular and genetic techniques. Additionally, journals dedicated to publishing OE studies are not typically high impact journals:

'We tend not to get into the really big journals, the Nature, Science and New England Journal of Medicine... but that is again partly because of the quality, I think, and partly because we just need people looking at the clever molecular cellular things. Also, editors judge ours [OE studies] with [studies using] new drugs, and we do not do that sort of stuff.' (P6).

\section{The Facilitators}

Under the facilitators theme, the following sub-themes were identified: effective communication; support and interest of the government and relevant stakeholders; availability and completeness of workers' or employees' records; availability of resources; and rigorous study design.

Effective communication

The key reported facilitator was effective communication with relevant stakeholders (e.g. industry management or employer, trade unions, workers, and employees) throughout a research study:

'A lot of input from me communicating with the workplaces, the workers, the unions. I did need them all for a lot of groundwork. I met with senior people within the workforce and got their permission to do it. I asked to meet the unions, and then through the unions I met the workers. So, I had several meetings and just a lot of time doing that [communication] compared to the scientific side.' (P7).

Support and interest of the government and relevant stakeholders

Another stated facilitator was the interest of key stakeholders (e.g. government, media, industry, employer, and public) in the issues under investigation: 
'...there was a public expectation that it [a particular research study] would be done. Because we said we were going to do it following on the initial study. So, we were being reminded by certain people from time to time; 'you said you are going to do this, where are the results?' And that I guess was filtering through to the people [industry management or employers] who had to allow us or not to use the information and helped to understand why we are doing it.' (P2).

'There was the media in newspapers and television; there was quite an interest in occupational cancer in 1970s. I think, prior to that, industry hadn't taken much notice. You had heavy industries, with very heavy exposures, and then things came to light as to whether really there was more occupational cancer than people thought. Industry then had to take notice.' (P4)

Availability and completeness of workers' or employees' records

The availability and completeness of records of the targeted workers or employees were thought to be important in facilitating certain OE studies:

'The crucial issue: what is the quality of the work history records in the factory records? In my opinion, there is no point in going back to individuals asking them to reconstruct their work history, because you will be introducing bias, people will not recall it in the same way. You want the contemporaneous record of what the company would've hopefully kept in a sort of similar way for all or most employees.

...it's the quality of the work histories which will then decide how sophisticated the analysis can be, in terms of whether you can estimate chemical exposures to different things etc. '(P4).

\section{Survey results}

\section{Participants}

The target sample comprised 144; 83 who were given questionnaires at the EPICOH Conference and 61 who received questionnaires through the post after the conference. Two potential participants returned a blank questionnaire and a note stating that they were not a suitable candidate to participate; another three blank questionnaires were returned without notes probably indicating that they also were not suitable candidates. After excluding those five individuals, the overall survey response rate from eligible participants was $38 \%(53 / 139)$ despite sending out two reminders.

The participants' levels of experience ranged from 3 to 35 years; approximately two thirds of them had 10 or more years of experience $(n=34,64 \%)$, and one third had less than 10 years $(\mathrm{n}=19,36 \%)$. They were working in various OE areas including; surveillance, exposure 
assessment, shift-work, health service research, mental health, ergonomics, musculoskeletal disorders, cancer and respiratory diseases. The majority of the participants had earned a $\mathrm{PhD}$ degree $(n=37,70 \%)$ as their highest professional degree, followed by MSc degree $(n=9$, $17 \%)$, and undergraduate degree $(n=3,6 \%)$, and other qualifications $(n=2,4 \%)$. More participants were working at universities $(n=24,45 \%)$ then in governmental bodies $(n=8$, $15 \%)$, and Research Institutes or charitable organisations $(n=7,13 \%)$. The roles of participants included: epidemiologists $(n=16,30 \%)$, physicians $(n=11,21 \%)$, occupational hygienist $(n=5,9 \%)$, statistician/epidemiologist $(n=9,17 \%)$, and other $(n=12,23 \%)$.

\section{The challenges}

The survey participants confirmed the challenges identified by the leading researchers in the interview phase, with slight variations on emphasis (Table 1). 'Low response to surveys' was the commonest challenge, whilst 'publication issues' was the least concern.

Table 1: Research challenges. Results are number (\%).

\section{The challenge statement}

1. There are not sufficient funding bodies/ opportunities for research in this field*

2. Online forms for grant applications are inappropriately designed for this type of research, which makes them difficult to complete*

3. Industry/employers do not cooperate or refuse access to data/participants (e.g. due to fear of litigation or prosecution) *

4. Agreement by industry/employers to access data/participants takes a long time, which delays the study*

5. Permission from occupational physician or GP to access participants' records is difficult to obtain*

6. NHS governance body approval to enable access to population/data is difficult to obtain*

7. It is difficult to carry out some studies (e.g. cohort studies) because of the requirement of the ethics committees for explicit

\begin{tabular}{|l|l|}
$\begin{array}{l}\text { Strongly } \\
\text { agree/Agree: } \\
\text { number }(\%)\end{array}$ & $\begin{array}{l}\text { Neither agree } \\
\text { nor disagree: } \\
\text { number }(\%)\end{array}$ \\
\hline $38(72)$ & $9(17)$ \\
\hline $15(28)$ & $30(57)$ \\
\hline
\end{tabular}

\section{Strongly \\ disagree/Disagree: \\ number (\%)}

$5(9)$

7 (13)

\begin{tabular}{l|l|l}
$20(38)$ & $22(42)$ & $10(19)$
\end{tabular}

$35(66) \quad 34(26) \quad 3(6)$

\begin{tabular}{l|l|l}
$31(58)$ & $17(32)$ & $4(8)$
\end{tabular}

$30(57) \quad 15(28) \quad 7(13)$

$35(66) \quad 8(15) \quad 8(15)$ 
informed consent**

8. The inconsistent interpretation of the ethical and governance frameworks (e.g. NHS Act (2006), DPA (1998)), by ethical and governance authorities, is causing difficulty in carrying out some research studies and following up some other ongoing studies*

9. There are many inappropriately designed forms required to complete for ethical and governance applications, thus delaying the application process*

10. Multi-centered studies are harder to set up, because of the unstandardised and the multiple approvals required by the governance bodies across centres*

11. It is difficult to get expert opinion on certain areas of occupational epidemiology, because there are few academic experts left in the $\mathrm{UK}^{*}$

12. Records of the workforce are not arranged in an accessible manner to facilitate research*

13. Early destruction of records for workers/employees is a major hurdle for conducting research studies*

14. It is difficult to carry out some research studies due to the inaccuracy and incompleteness of the workers'/employees' records

15. A low response/participation rate is a major difficulty facing researchers in many studies

16. When a study's findings are made available to the workforce in the first instance, it is then harder to get them published in a scientific journal*

17. It is difficult to convince industry to agree to publish negative study findings*

30

$30(57)$

19 (36)

$3(6)$

$4(8)$

$24(45)$

$14(26)$

$14(26)$

$43(81)$

$9(17)$

$0(0)$

$22(42)$

25 (47)

5 (9)

$36(68)$

$16(30)$

$46(87)$

$3(6)$

$4(8)$

$2(4)$

26 (49)

$24(45)$

$13(25)$

25 (47)

14 (26)

* Missing data from one participant

** Missing data from two participants 


\section{Results from open-ended questions}

Thirty participants (57\%) experienced delays in starting their studies primarily due to delays in gaining ethics and other research governance approvals, and recruitment difficulties. Nine participants $(17 \%)$ were forced to prematurely end their studies due to recruitment difficulties. Another nine researchers (17\%) said that their studies were compromised because of poor response rates, limited funding, and ethics and governance clearance delays. The most prevalent challenges reported were funding $(\mathrm{n}=18)$, ethics and governance approvals $(\mathrm{n}=12)$ and recruitment issues $(\mathrm{n}=8)$.

\section{The Facilitators}

As shown in Table 2, the participants generally agreed with all facilitator statements. The government support and interest in conducting OE studies was perceived to be the most important facilitator.

Table 2: Research facilitators

\section{The facilitator statement \\ 1. Support from trade unions/work representatives facilitates the conduct of research studies* \\ 2. The role of the media is important in applying pressure on industry/employers for a particular disease/problem to be investigated*}

3. The media can help to advertise a particular study, and thus improve the study response/participation rate*

4. Government interest and pressure for a particular disease/problem to be investigated facilitate the conduct of such studies

5. Pre-study formal and informal negotiations and discussions with relevant stakeholders to obtain approval is important*

6. Keeping stakeholders involved by communicating with them about the study and following up unresolved issues*

7. Studies carried out by or on behalf of the relevant regulatory bodies (e.g. Health and Safety Executive "HSE") are easier to get approvals and cooperation from the relevant

\begin{tabular}{|l|l|l|}
\hline $\begin{array}{l}\text { Strongly } \\
\text { agree/Agree } \\
\text { number (\%) }\end{array}$ & $\begin{array}{l}\text { Neither agree } \\
\text { nor disagree } \\
\text { number (\%) }\end{array}$ & $\begin{array}{l}\text { Strongly } \\
\text { disagree/Disagree } \\
\text { number (\%) }\end{array}$ \\
\hline $42(79)$ & $8(15)$ & $2(4)$ \\
\hline $31(58)$ & $17(32)$ & $4(8)$ \\
\hline
\end{tabular}

\begin{tabular}{l|l|l}
$30(57)$ & $17(13)$ & $5(9)$
\end{tabular}

$48(91) \quad 3(6) \quad 1(2)$

\begin{tabular}{l|l|l}
$46(87)$ & $6(11)$ & $0(0)$
\end{tabular}

\begin{tabular}{l|l}
$44(83)$ & $7(13)$ \\
\hline
\end{tabular}

\begin{tabular}{l|l|l}
$27(51)$ & $21(40)$ & $4(8)$
\end{tabular} 
stakeholders*

8. Studies that have been designed to fill specific gaps in government or other policies are easier to get approvals and cooperation from the relevant stakeholders*

$35(66) \quad 17(32) \quad 0(0)$

9. Data from previous large and well-designed epidemiological studies can be exploited to $43(81) \quad 9(17) \quad 1$ (2) facilitate current studies

*Missing data from one participant

\section{Results from open-ended questions}

No additional facilitators were identified by respondents. Participants were also asked to state the most important facilitators. Thirty-five participants responded and the most important facilitators reported were: support from trade unions/work representatives $(n=10)$; government interest $(\mathrm{n}=10)$; using data from large epidemiological studies $(\mathrm{n}=9)$; and prestudy negotiation to obtain approvals $(\mathrm{n}=8)$.

\section{Discussion}

This study provides evidence on the challenges and facilitators of UK-based OE research. Lack of resources and worsening challenges over the years are the main reported difficulties affecting the current and potentially future development of this field. Consequently, there is an indication that the $\mathrm{OE}$ community has become smaller and more scattered, and hence increasingly less influential. Support from government and relevant stakeholders, and effective communication strategies and networking with key stakeholders, are the main reported facilitators.

These challenges can be more problematic for OE compared to other fields. This is because of the specific characteristics of this field, particularly when potential participants can only be found in a specific industry/employment and the industry management or employer has the primary power in deciding whether or not researchers can access these potential participants and/or their health records. Industry management or employers may, however, refuse access to participants and data for various reasons, such as fear of litigation or work disruption.

Although the focus of the study was on $\mathrm{OE}$, it was obvious that issues in relation to $\mathrm{OH}$ research and OHS in general, are also related to the field of OE. Key researchers interviewed in this study had quite often referred to $\mathrm{OH}$ issues when discussing $\mathrm{OE}$ challenges and facilitators. This is because some of these researchers were involved in the broader field of $\mathrm{OH}$ research that included OE. Furthermore, OE studies would be difficult to conduct if the $\mathrm{OH}$ field and services were not well established. For example, to conduct a cohort study, $\mathrm{OH}$ data might be required from employees' or workers' health records held by the industry or 
employer, or/and from their medical records held by a GP surgery, an NHS hospital and NHS Digital.

Key discussion points are detailed in the next discussion sub-sections.

\section{Lack of resources}

The study indicates that the OE field in the UK is seriously lacking human and financial resources. It has become difficult to attract new researchers to this area and leading researchers were reported to be approaching retirement. For example, 457 (67\%) Members and Fellows of the Faculty of Occupational Medicine (FOM) were 50 years old or older in 2011, giving a clear indication of the ageing workforce (Faculty of Occupational Medicine, 2011). Furthermore, the FOM have since highlighted the decline in the number of posts and doctors seeking training in occupational medicine (Faculty of Occupational Medicine, 2016). Similarly, the Society of Occupational Medicine has experienced a steady attrition in its membership due to the ageing population of the wider $\mathrm{OH}$ professionals and the lack of new entrants (Society of Occupational Medicine, 2017).

There is a real concern about the sustainability of the $\mathrm{OH}$ workforce and academic base in the UK (Faculty of Occupational Medicine, 2011; Harrison, 2012; Lalloo et al., 2019a; Society of Occupational Medicine, 2017). One potential reason for the diminishing workforce in OE and its academic base is the exclusion of OHS from the NHS since its inception (Long, 2011). Thus, the negative impact of this separation of OHS from the NHS on both OH and $\mathrm{OE}$ is inevitable in terms of their diminishing academic bases, training, and research (Blain, 1988; Harrison, 2012). Unsurprisingly, the OE infrastructure might have become insufficient to keep pace with methodological development and maintain the highest academic standards and research quality (Lalloo et al., 2019a). These issues may not only limit the resources available for this research field, but also restrict the control that $\mathrm{OE}$ (and $\mathrm{OH}$ ) researchers have over the research agenda, as fewer and less influential representatives are available for and involved in funding decisions and policy making. If measures are not taken to address the challenges and increase the opportunities in OE field, the decline in occupational epidemiological knowledge base will continue (Ward et al., 2010) and UK health and safety policy-making will become increasingly reliant on non-UK studies (Industrial Injuries Advisory Council, 2011). Relying on non-UK epidemiological studies or studies from the past is problematic, because exposure data from such studies may not reflect the level of exposure experienced in a UK workplace (Rushton, 2017; Rushton et al., 2012). The difference in exposure between countries and over time may arise due to differences in regulations, technology, social class, culture, geography, and methods of exposure measurement (Cherrie et al., 2007). 


\section{Declining interest in OE field}

$\mathrm{OE}$, and $\mathrm{OH}$ research in general, have also been weakened by the progressive lack of interest and investment in developing well-established programmes in this field from educational, governmental, and other research-funding bodies. As a result of past and ongoing improvement of workplace conditions and establishment of exposure standards, there is a perception that, other than psychosocial and musculoskeletal problems, OH-related diseases are now a thing of the past, mainly because control of exposures is probably seen as the endpoint of the disease prevention effort (Chen and Osman, 2012). Another factor likely to be contributing to this lack of interest is the decline in heavy industry in the UK. The transformation of the nature of employment and the labour market during recent decades has resulted in a sharp decrease in the number of workers employed in hazardous industries (e.g. mining, rubber) relative to the numbers employed in service industries (e.g. banking, retail) (Floud et al., 2014, pp. 7-8). For instance, the number employed in the coal industry in the UK declined from 300,000 in the early 1970s to only 1,000 in 2017 (Department for Business, Energy \& Industrial Strategy, 2018), and employment in manufacturing industries declined from 8,909,000 in 1964 to 2,515,000 in 2010 (Griffiths and Wall, 2011, p. 9).

With the decrease in classical hazardous industries, the delivery of $\mathrm{OH}$ has gradually shifted from in-house to contracted-out services (Guidotti, 2013). This trend has resulted in the reduction of the influence of $\mathrm{OH}$ professionals (including occupational epidemiologists) within industries, less engagement in the employers' specific needs, and loss of knowledge about the workplace circumstances and environment (Guidotti, 2013). Also, compared to external OHS, in-house OHS are generally superior in terms of identifying potential occupational risks that merit investigating, ease of gaining access to data and participants, and achieving the highest process quality of care (Valk et al., 2006).

Nevertheless, although many occupational risks have been addressed, several new workplace hazards (e.g. nanomaterials) have been identified, and many others (e.g. psychosocial risks) have not yet been removed (Chen and Osman, 2012). There are also re-emerging opportunities for OE in other areas such as outdoor air pollution that could potentially affect the workplace environment and workforce health (Landrigan et al., 2018). As implied by this study's participants and supported by other research, there has been a reduction in OE research outputs, which reflects the limited current scientific efforts in this field worldwide (Blair et al., 2013; Hohenadel et al., 2011; Lalloo et al., 2019a; Smith and Leggat, 2006). For instance, the number of suspected occupational carcinogens identified from 1964 until 1982 increased by about 1000\%, whilst between 1982 and 2003 the increase was approximately $50 \%$ (Blair et al., 2013). 


\section{Lack of expertise and innovative methodologies}

This study highlights the participants' beliefs that the current lack of innovative methodologies in $\mathrm{OE}$ is making it less attractive to potential funders and researchers. Similarly, other international organisations have concluded that, although there have been multidisciplinary efforts to develop cancer research methods, these have not been broadly utilised to solve important issues within the occupational cancer field and have therefore recommended the development of innovative methods and tools (Hohenadel et al., 2011; Ward et al., 2003). In light of the challenges and the developments in methodological approaches in other health disciplines (Spitz et al., 2014; Ward et al., 2003), it is becoming more challenging for $\mathrm{OE}$ to compete for funding and attract younger researchers. The likely main reasons for this lack of innovation are an ageing workforce and fewer researchers entering this field with sufficient expertise in new technologies and techniques (e.g. molecular and genetic techniques, and psychosocial, musculoskeletal and health economic approaches). The study respondents hence recommended a better collaborative approach with other disciplines to facilitate the inclusion of new expertise and innovative methodologies.

\section{Access to participants and records}

Obtaining ethics and other research governance clearances was thought to be another obstacle for conducting $\mathrm{OE}$ research. The current ethical and research governance framework in the UK are designed for high-risk studies that use medical interventions primarily on patient populations. These regulations are still imposed on OE studies at a similar level despite the fact that these are primarily observational in nature and are generally low-risk studies in terms of potential harm to participants (Cardillo et al., 2018; Leeson and Tyrer, 2013; Petrova and Barclay, 2019; Ward et al., 2004). The Health Research Authority introduced the Proportionate Review Service (PRS), under which research studies which raise no material ethical issues will be reviewed by sub-committee rather than at a full meeting of a REC with an aim to make a decision within 14 days of the research proposal application (Health Research Authority, 2020). The eligible studies for PRS are primarily those that use anonymised data, utilised no linkage to patients' identifiable data and those that use questionnaires or interviews that are not sensitive in nature. These key criteria are generally not applicable to most epidemiological studies, resulting in the same ethics processes being applied to OE studies as to randomised controlled trials of medical interventions.

Another important factor for conducting $\mathrm{OE}$ is the existence of occupational records for workers exposed to new or currently unknown hazards (Lightfoot et al., 2003). However, the existence and completeness of these records are entirely dependent on the standard practices of a particular company or employer. Some companies have prematurely destroyed the workers' records (Betts and Rushton, 1998; Rushton et al., 2010; Rushton and Betts, 2001) and others may not have collected or partially recorded exposure data for their workers (Cherrie et al., 2007). Assessing the availability, completeness and accuracy of information 
required for a study prior to it being carried out is a viable approach (Cherrie et al., 2001). However, it is not always practically possible to assess the information sources for completeness and accuracy prior to the study due to access restrictions and confidentiality laws (Coggon, 2001).

\section{Study strengths and weaknesses}

Using a mixed-methods approach has strengthened this study's findings. The qualitative phase provided a clear picture of the barriers to and facilitators of conducting OE research in the UK. However, in isolation, the qualitative phase imposed a limitation in relation to the generalisability of its findings, due to the small number of researchers interviewed. Therefore, a survey was undertaken to examine the research topic with a larger population of OE researchers. The questionnaire design could have been enhanced by including a pilot. Nonetheless, the survey results confirmed the findings from the interview phase, adding robustness to the study's overall conclusions.

For the survey, although several approaches were used to identify as many potential participants as possible, having no sampling frame from which to select active UK-based OE researchers, it was not possible to ascertain if they were representative of the target population. Furthermore, the low response rate lessens the validity of the study findings. Another approach to get a better representation of a wider group of OE researchers would have been through contacting potential participants via the Faculty of Occupational Medicine, which has a medical practitioner membership, and the Society of Occupational Medicine, which includes both medical and non-medical professionals' members. However, not all members of these two bodies are research active and not all active researchers are members of these bodies, hence it is unclear as to whether these sources would have provided a better sampling frame. Nonetheless, this issue could have been explained in the questionnaire cover letter. On the other hand, a recent study in this field reported an $18 \%$ response rate using an online survey of members of the Faculty of Occupational Medicine (Lalloo et al., 2019a), indicating similar challenges in obtaining responses from this group.

\section{Recommendation}

We echo the recommendations of a recent report published by the Society of Occupational Medicine, particularly the need for: a coordinating body to provide leadership on $\mathrm{OH}$ research, including improving dissemination of findings and translation into practice; a national $\mathrm{OH}$ research strategy to progress the research agenda and inform policy development; retaining and developing the $\mathrm{OH}$ academic base to support and attract new researchers to the field; identifying current and future priorities in this field; integration of technological advances and incorporation of more innovative methodologies into this field; and increasing funding and investment in $\mathrm{OH}$ research (Lalloo et al., 2019b). Furthermore, 
for $\mathrm{OE}$ to develop, OE researchers need to engage in social, economic and political matter, be open to new advances in research methodology, make the OE field attractive to early career researchers and optimise networking opportunities with other disciplines and stakeholders.

The OE community and key leaders need to review the field's work, to identify achievements, failures, and to prioritise future issues that are most likely to affect the workforce health and prioritise areas of research. In order to justify strongly for increased public and other sources of funding for $\mathrm{OE}$ and $\mathrm{OH}$ research, and then use the scarce research resources efficiently and effectively, there should also be clear decisions about research priorities. These priorities must be consistent not only with informed scientific opinion but also with relevant stakeholders' needs and national concerns within the broader policy context. A recent study has already highlighted $\mathrm{OH}$ research priorities in the UK (Lalloo et al., 2018). Such an organised review could persuade policy makers and funding bodies to increase resources to this field. Based on this comprehensive review, resources need to be directed to prepare and train young scientists to pursue research in these priority areas. Funding policies should not only focus on the immediate or measurable economic return from research studies. OE research may not necessarily provide a visible benefit or an immediate economic return; however, it may have long-term public health and economic benefits (Robertson, 2015).

OE researchers should be open to collaborate with other scientists from other fields who could bring new insights and expertise to this field. OE should not work in isolation from other public health disciplines, as this will only lead to further isolation and challenges to the field. Its importance is rooted in its public health contributions. Thus, researchers should take every opportunity to participate and be involved in collaborative studies examining the illhealth and injuries from different perspectives using different approaches.

Another concern is the quality and existence of workers' and employees' records, particularly those within industry and small and medium-sized enterprises. Leaders, policy makers and relevant stakeholders in this field should consider strategies and guidelines to establish, maintain and retain these records whilst considering facilitating future research.

\section{Further research}

Further investigation, using different approaches, is required to confirm the identified challenges and facilitators and to understand better why and when some of these challenges started to occur, and whether these have been experienced in other health research fields. Further research is also required to assess the productivity of the field of OE over time compared to other similar fields. This will help to assess objectively the potential trends in the rise and fall of research output and to identify gaps and the reasons for these. It is also important to assess systematically key UK stakeholders' (e.g. funding bodies, government 
bodies and universities) policies and processes to understand how and why decisions are or were made in relation to supporting $\mathrm{OH}$ research compared to other fields.

\section{Conclusion}

Although the fieldwork for this study was conducted in 2011, the issues identified remain relevant and supported by recent evidence (Lalloo et al., 2019b). The OE field has been influenced by the rise and fall of $\mathrm{OH}$ in the UK, which, in turn, has been influenced by social, economic and political factors such as the deindustrialisation, the exclusion of $\mathrm{OH}$ from the NHS, and funding policies. This may have contributed to the relative obscurity of $\mathrm{OH}$, and hence OE, when the agendas of both the government and funding bodies are developed, adversely affecting the development of $\mathrm{OE}$. Consequently, $\mathrm{OH}$ and safety policies may increasingly have to rely on non-UK studies, which may not sufficiently address UK workforce health issues. Maintaining UK-based OE research is hence necessary for the future development of appropriate occupational health services and policies for the UK workforce. 


\section{References}

Betts, D., Rushton, L., 1998. The feasibility of conducting occupational epidemiology in the UK. Occup. Med. 48, 433-439.

Black, D.C., 2008. Working for a healthier tomorrow: work and health in Britain. London: TSO.

Blain, P.G., 1988. Occupational health research. BMJ 297, 1043-1044.

Blair, A., Hohenadel, K., Demers, P., Marrett, L., Straif, K., 2013. Prevention of Occupationally Induced Cancer, in: Miller, A.B. (Ed.), Epidemiologic Studies in Cancer Prevention and Screening. Springer New York, pp. 33-43.

Cardillo, L., Cahill, F., Wylie, H., Williams, A., Zylstra, J., Davies, A., Fullwood, L., Van Hemelrijck, M., 2018. Patients' perspectives on opt-out consent for observational research: systematic review and focus group. Br. J. Nurs. 27, 1321-1329. https://doi.org/10.12968/bjon.2018.27.22.1321

Checkoway, H., Pearce, N.E., Kriebel, D., 2004. Research Methods in Occupational Epidemiology, 2 nd. ed. OUP USA, New York.

Chen, Y., Osman, J., 2012. Occupational cancer in Britain. Br. J. Cancer 107, S104-S108. https://doi.org/10.1038/bjc.2012.125

Cherrie, J.W., Sewell, C., Ritchie, P., Mclntosh, C., Tickner, J., Llewellyn, D., 2001. Retrospective Collection of Exposure Data from Industry: Results from a Feasibility Study in the United Kingdom. Appl. Occup. Environ. Hyg. 16, 144-148. https://doi.org/10.1080/104732201460235

Cherrie, J.W., Tongeren, M.V., Semple, S., 2007. Exposure to Occupational Carcinogens in Great Britain. Ann. Occup. Hyg. 51, 653-664. https://doi.org/10.1093/annhyg/mem049

Coggon, D., 2005. Occupational medicine at a turning point. Occup. Environ. Med. 62, 281-283. https://doi.org/10.1136/oem.2004.017335

Coggon, D., 2001. Ethics in occupational health research. Occup. Environ. Med. 58, 685-688.

Cohen, L., Manion, L., Morrison, K., 2011. Research Methods in Education, 7th Revised edition. ed. Routledge Falmer, Abingdon; New York.

Department for Business, Energy \& Industrial Strategy, 2018. Digest of UK Energy Statistics (DUKES): solid fuels and derived gases.

Department for Work and Pensions and Department of Heal, 2016. Work, Health and Disability Green Paper Data Pack 61.

Dimakakou, E., Johnston, H.J., Streftaris, G., Cherrie, J.W., 2018. Exposure to Environmental and Occupational Particulate Air Pollution as a Potential Contributor to Neurodegeneration and Diabetes: A Systematic Review of Epidemiological Research. Int. J. Environ. Res. Public. Health 15. https://doi.org/10.3390/ijerph15081704.

Etikan, I., 2016. Comparison of Convenience Sampling and Purposive Sampling. Am. J. Theor. Appl. Stat. 5, 1. https://doi.org/10.11648/j.ajtas.20160501.11.

Faculty of Occupational Medicine, 2016. Faculty of Occupational Medicine Annual report and accounts 2016.

Faculty of Occupational Medicine, 2011. The Future Need for Specialist Occupational Physicians in The UK. A Report By The Faculty Of Occupational Medicine.

Faculty of Occupational Medicine, 2006. Position Statement Provision of Occupational Health University Press.

Floud, R., Humphries, J., Johnson, P., 2014. The Cambridge Economic History of Modern Britain. Cambridge University Press.

Fusch, P., Ness, L., 2015. Are We There Yet? Data Saturation in Qualitative Research. Qual. Rep. 20, 1408-1416.Graber, J.M., Cohen, R.A., Miller, B.G., Stayner, L.T., 2013. Increased morbidity and mortality among coal workers, in: Venables, K. (Ed.), Current Topics in Occupational Epidemiology. Oxford University Press, pp. 3-16. 
https://doi.org/10.1093/med/9780199683901.003.0001Griffiths, M.A., Wall, S., 2011. Applied

Economics, 12 ed. Financial Times/ Prentice Hall, Harlow, Essex; New York, NY.

Guidotti, T.L. (Ed.), 2013. Occupational health services: a practical approach, 2nd ed. Routledge/Taylor

\& Francis Group, Abingdon, Oxon.

Guidotti, T.L., 2000. Occupational epidemiology. Occup. Med. Oxf. Engl. 50, 141-145.

Hagger-Johnson, G., Harron, K., Fleming, T., Gilbert, R., Goldstein, H., Landy, R., Parslow, R.C., 2015.

Data linkage errors in hospital administrative data when applying a pseudonymisation algorithm

to paediatric intensive care records. BMJ Open 5, e008118. https://doi.org/10.1136/bmjopen2015-008118

Harrison, J., 2012. A future forum for UK occupational health? Occup. Med. 62, 590-591. https://doi.org/10.1093/occmed/kqs155

Health and Safety Executive, 2017. Health and safety at work: Summary statistics for Great Britain 2017 (No. hssh0910). Health and Safety Executive, Crown copyright.

Health Research Authority, 2020. Applying to a Research Ethics Committee [WWW Document]. Health Res. Auth. URL /approvals-amendments/what-approvals-do-i-need/research-ethics-committeereview/applying-research-ethics-committee/ (accessed 3.1.20).

Hohenadel, K., Pichora, E., Marrett, L., Bukvic, D., Brown, J., Harris, S.A., Demers, P.A., Blair, A., 2011. Priority issues in occupational cancer research: Ontario stakeholder perspectives. Chronic Dis. Inj. Can. 31, 147-151.

Hotopf, M., Wessely, S., 2005. Can epidemiology clear the fog of war? Lessons from the 1990-91 Gulf War. Int. J. Epidemiol. 34, 791-800.

IBM Corp., 2010. IBM SPSS Statistics for Windows. IBM Corp., Armonk, NY.

Industrial Injuries Advisory Council, 2011. Lung cancer in coke oven workers: report by the Industrial Injuries Advisory Council in accordance with section 171 of the Social Security Administration Act 1992 considering prescription for Lung cancer in coke oven workers. Stationery Office, London.

International Labour Office, 2009. Identification and recognition of occupational diseases: criteria for incorporating diseases in the ILO list of occupational diseases, Meeting of Experts on the Revision of the List of Occupational Diseases (Recommendation No. 194) (Geneva, 27-30 October 2009). ILO, Geneva.

Lalloo, D., Demou, E., Pahl, N., Macdonald, E.B., 2019a. Research and teaching activity in UK occupational physicians. Occup. Med. https://doi.org/10.1093/occmed/kqz132

Lalloo, D., Demou, E., Smedley, J., Madan, I., Asanati, K., Macdonald, Ewan.B., 2018. Current research priorities for UK occupational physicians and occupational health researchers: a modified Delphi study. Occup. Environ. Med. 75, 830-836. https://doi.org/10.1136/oemed2018-105114

Lalloo, Drushca, Macdonald, E., Vargas-Prada Figueroa, S., Germeni, E., Mclntosh, E., 2019b. The Value of Occupational Health Research: History, Evolution and Way Forward [WWW Document]. URL http://eprints.gla.ac.uk/189614/ (accessed 2.29.20).

Landrigan, P.J., Fuller, R., Acosta, N.J.R., Adeyi, O., Arnold, R., Basu, N. (Nil), Baldé, A.B., Bertollini, R., Bose-O'Reilly, S., Boufford, J.I., Breysse, P.N., Chiles, T., Mahidol, C., Coll-Seck, A.M., Cropper, M.L., Fobil, J., Fuster, V., Greenstone, M., Haines, A., Hanrahan, D., Hunter, D., Khare, M., Krupnick, A., Lanphear, B., Lohani, B., Martin, K., Mathiasen, K.V., McTeer, M.A., Murray, C.J.L., Ndahimananjara, J.D., Perera, F., Potočnik, J., Preker, A.S., Ramesh, J., Rockström, J., Salinas, C., Samson, L.D., Sandilya, K., Sly, P.D., Smith, K.R., Steiner, A., Stewart, R.B., Suk, W.A., Schayck, O.C.P. van, Yadama, G.N., Yumkella, K., Zhong, M., 2018. 
The Lancet Commission on pollution and health. The Lancet 391, 462-512.

https://doi.org/10.1016/S0140-6736(17)32345-0

Leeson, V.C., Tyrer, P., 2013. The advance of research governance in psychiatry: one step forward, two steps back. Epidemiol. Psychiatr. Sci. 22, 313-320.

https://doi.org/10.1017/S2045796013000255

Long, V., 2011. The rise and fall of the healthy factory: the politics of industrial health in Britain, 1914-

60. Palgrave Macmillan, Basingstoke.

Newill, V.A., 1983. Overview of occupational epidemiology: issues/dilemmas. J. UOEH 5 Suppl, 15-28.

Nowell, L.S., Norris, J.M., White, D.E., Moules, N.J., 2017. Thematic Analysis: Striving to Meet the Trustworthiness Criteria. Int. J. Qual. Methods 16, 1609406917733847. https://doi.org/10.1177/1609406917733847

Patton, M., 2002. Qualitative research and evaluation methods, 3rd. ed. Sage Publications, Thousand Oaks Calif.

Peckham, T.K., Baker, M.G., Camp, J.E., Kaufman, J.D., Seixas, N.S., 2017. Creating a Future for Occupational Health. Ann. Work Expo. Health 61, 3-15. https://doi.org/10.1093/annweh/wxw011

Petrova, M., Barclay, S., 2019. Research approvals iceberg: how a 'low-key' study in England needed 89 professionals to approve it and how we can do better. BMC Med. Ethics 20, 7. https://doi.org/10.1186/s12910-018-0339-5

Robertson, H., 2015. The Health and Safety at Work Act turned 40. Occup. Med. 65, 176-179. https://doi.org/10.1093/occmed/kqv007

Rushton, L., 2017. The Global Burden of Occupational Disease. Curr. Environ. Health Rep. 4, 340-348. https://doi.org/10.1007/s40572-017-0151-2

Rushton, L., Bagga, S., Bevan, R., Brown, T.P., Cherrie, J.W., Holmes, P., Fortunato, L., Slack, R., Van Tongeren, M., Young, C., Hutchings, S.J., 2010. Occupation and cancer in Britain. Br. J. Cancer 102, 1428-1437. https://doi.org/10.1038/sj.bjc.6605637

Rushton, L., Betts, D.S., 2001. Exposure information in European industry: implications for future occupational research. Appl. Occup. Environ. Hyg. 16, 178-181.

Rushton, L., Hutchings, S.J., Fortunato, L., Young, C., Evans, G.S., Brown, T., Bevan, R., Slack, R., Holmes, P., Bagga, S., Cherrie, J.W., Van Tongeren, M., 2012. Occupational cancer burden in Great Britain. Br. J. Cancer 107, S3-S7. https://doi.org/10.1038/bjc.2012.112.

Schoonenboom, J., Johnson, R.B., 2017. How to Construct a Mixed Methods Research Design. Kolner Z. Soziol. Sozialpsychologie 69, 107-131. https://doi.org/10.1007/s11577-017-0454-1

Smith, D.R., Leggat, P.A., 2006. The historical development and future challenges for occupational health services in Australia. Int. Congr. Ser. 1294, 69-70.

Society of Occupational Medicine, 2017. Trustees' report and financial statements for the year ended 31 December 2016. London.

Spitz, M.R., Lam, T.K., Schully, S.D., Khoury, M.J., 2014. The Next Generation of Large-Scale Epidemiologic Research: Implications for Training Cancer Epidemiologists. Am. J. Epidemiol. 180, 964-967. https://doi.org/10.1093/aje/kwu256

Stayner, L.T., Collins, J.J., Guo, Y.L., Heederik, D., Kogevinas, M., Steenland, K., Wesseling, C., Demers, P.A., 2017. Challenges and Opportunities for Occupational Epidemiology in the Twenty-first Century. Curr. Environ. Health Rep. 4, 319-324. https://doi.org/10.1007/s40572017-0154-z

Tashakkori, A., Teddlie, C., 2010. SAGE Handbook of Mixed Methods in Social \& Behavioral Research. SAGE. 
Teddlie, C., Tashakkori, A., 2008. Foundations of mixed methods research: integrating quantitative and qualitative approaches in the social and behavioral sciences. Sage Publications, Thousand Oaks.

Valk, M.M.A.D., Oostrom, C., Schrijvers, A.J.P., 2006. An assessment of occupational health care in the Netherlands (1996-2005). Occup. Med. 56, 475-479. https://doi.org/10.1093/occmed/kql074

Vanhoorne, M., Harrington, J.M., Parmeggiani, L., Hunter, W., Baert, A., Vuylsteek, K., 1985. Constraints in the development of occupational health research and its application. Int. Arch. Occup. Environ. Health 55, 337-349. https://doi.org/10.1007/BF00377692

Vaughan-Jones, H., Barham, L., 2009. Healthy Work 2030: Challenges and Opportunities to 2030. BUPA.

Ward, E.M., Schulte, P.A., Bayard, S., Blair, A., Brandt-Rauf, P., Butler, M.A., Dankovic, D., Hubbs, A.F., Jones, C., Karstadt, M., Kedderis, G.L., Melnick, R., Redlich, C.A., Rothman, N., Savage, R.E., Sprinker, M., Toraason, M., Weston, A., Olshan, A.F., Stewart, P., Zahm, S.H., 2003. Priorities for development of research methods in occupational cancer. Environ. Health Perspect. 111, 1-12.

Ward, E.M., Schulte, P.A., Straif, K., Hopf, N.B., Caldwell, J.C., Carreón, T., DeMarini, D.M., Fowler, B.A., Goldstein, B.D., Hemminki, K., others, 2010. Research recommendations for selected IARC-classified agents. Env. Health Perspect 118, 1355-1362.

Ward, H.J.T., Cousens, S.N., Smith-Bathgate, B., Leitch, M., Everington, D., Will, R.G., Smith, P.G., 2004. Obstacles to conducting epidemiological research in the UK general population. BMJ 329, 277-279. https://doi.org/10.1136/bmj.329.7460.277

Wegman, D.H., 2014. Challenges for occupational epidemiology in the 21st century: observations and opportunities. Occup. Environ. Med. 71, 739-741. https://doi.org/10.1136/oemed-2014-102487 


\section{Supplementary Material}

\section{The study Questionnaire}

\section{Research Challenges}

a) We would like to know the extent to which you think each of the following situations is a challenge in carrying out occupational epidemiology research in the UK.

For each item, please circle the response that best represents your view, where $1=$ strongly agree, $2=$ agree, $3=$ neither agree nor disagree, $4=$ disagree, and $5=$ strongly disagree. If you change your mind, please cross out the original response, and circle the correct one.

\section{The challenge statement}

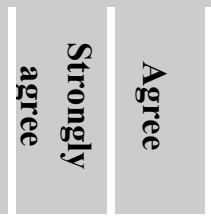

- There are not sufficient funding bodies/ opportunities for research in this field

2. Online forms for grant applications are inappropriately designed for this type of research, which makes them difficult to complete

3. Industry/employer do not cooperate or refuse access to data/participants (e.g. due to fear of litigation or prosecution)

4. Agreement by industry/employer to access data/participants takes a long time, which delays the study

5. Permission from occupational physician or GP to access participants' records is difficult to obtain

6. NHS governance body approval to enable access to population/data is difficult to obtain

7. It is difficult to carry out some studies (e.g. cohort studies) because of the requirement of the ethics committees for explicit informed consent

8. The inconsistent interpretation of the ethical and governance frameworks (e.g. NHS Act (2006), DPA (1998)), by ethical and governance authorities, is causing difficulty in carrying out some research studies and following up some other ongoing studies

9. There are many inappropriately designed forms required to complete for ethical and governance applications, thus delaying the application process

10. Multi-centered studies are harder to set up, because of the unstandardised and the multiple approvals required
1

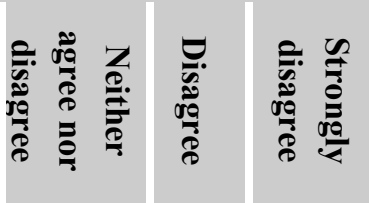

\begin{tabular}{l|l|l|l|}
2 & 3 & 4 & 5
\end{tabular}
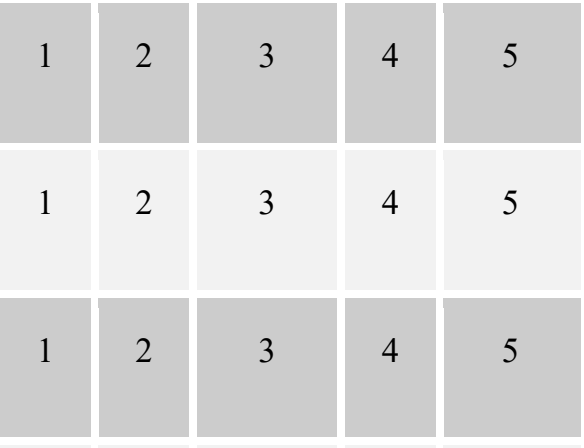

\begin{tabular}{l|l|l|l|l|}
1 & 2 & 3 & 4 & 5
\end{tabular}

\begin{tabular}{|l|l|l|l|l|}
\hline 1 & 2 & 3 & 4 & 5 \\
\hline
\end{tabular}

\begin{tabular}{l|l|l|l|l|}
1 & 2 & 3 & 4 & 5
\end{tabular}

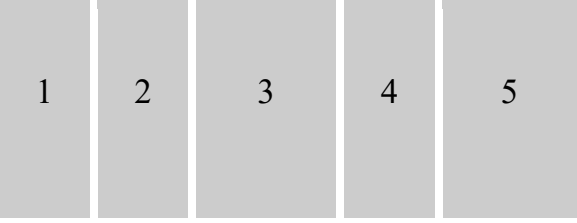

\begin{tabular}{l|l|l|l|l|}
1 & 2 & 3 & 4 & 5
\end{tabular}

\begin{tabular}{l|l|l|l|l}
1 & 2 & 3 & 4
\end{tabular}


by the governance bodies across centres.

11. It is difficult to get expert opinion on certain areas of occupational epidemiology, because there are few academic experts left in the UK

12. Records of the workforce are not arranged in an accessible manner to facilitate research

13. Early destruction of records for workers/employees is a major hurdle for conducting research studies

14. It is difficult to carry out some research studies due to the inaccuracy and incompleteness of the workers'/employees' records

15. A low response/participation rate is a major difficulty facing researchers in many studies

16. When a study's findings are made available to the workforce in the first instance, it is then harder to get them published in a scientific journal

17. It is difficult to convince industry to agree to publish negative study findings

\begin{tabular}{|l|l|l|l|l|}
\hline 1 & 2 & 3 & 4 & 5 \\
\hline 1 & 2 & 3 & 4 & 5 \\
\hline 1 & 2 & 3 & 4 & 5 \\
\hline 1 & 2 & 3 & 4 & 5 \\
\hline 1 & 2 & 3 & 4 & 5 \\
\hline 1 & 2 & 3 & 4 & 5 \\
\hline 1 & 2 & 3 & 4 & 5 \\
\hline
\end{tabular}

Please state any other issues, not mentioned above, you think are challenges to occupational epidemiology research

b) Which challenges from the above do you consider are the most important, and why?

c) What strategies have you employed to overcome the challenges you have experienced (e.g. Changing the study design, appeal against study disapproval)?

d) Why you have used these strategies?

e) Were these strategies successful?

\section{Facilitators}


f) We would like to know the extent to which you think each of the following situations is a facilitator to occupational epidemiology research in the UK?

For each item, circle the response that best represents your view, where $1=$ strongly agree, $2=$ agree, $3=$ neither agree nor disagree, $4=$ disagree, and $5=$ strongly disagree. If you change your mind, please cross out the original response, and circle the correct one.

The facilitator statement

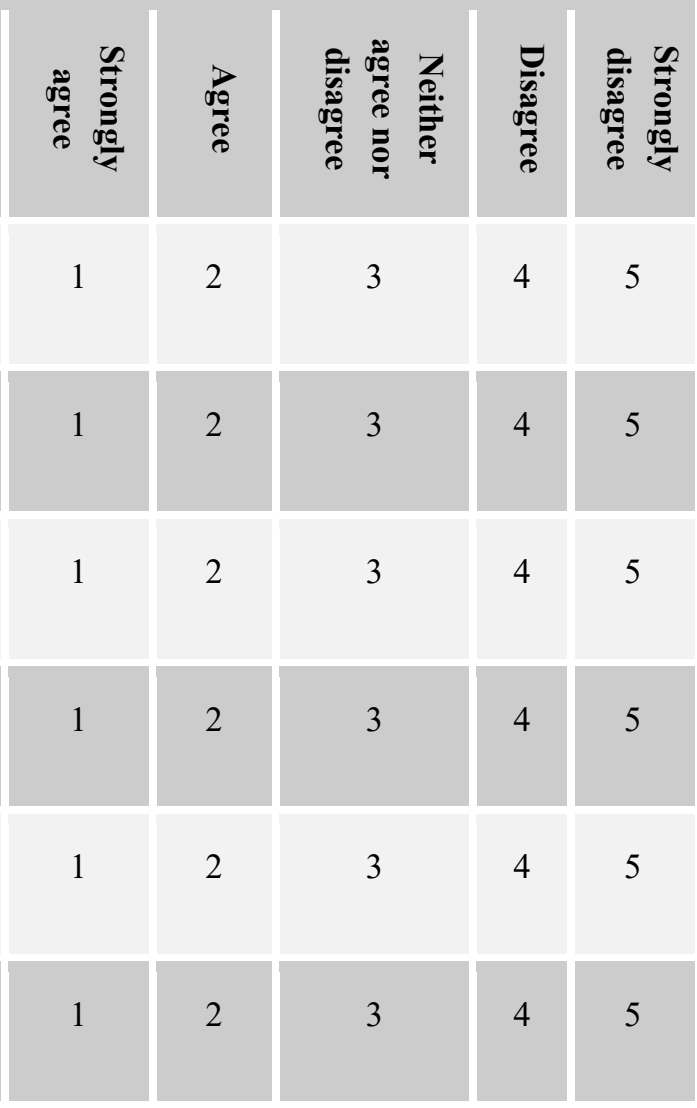

1. Support from trade unions/work representatives facilitates the conduct of research studies

2. The role of the media is important in applying pressure on industry/employers for a particular disease/problem to be investigated

3. The media can help to advertise a particular study, and thus improve the study response/participation rate

4. Government interest and pressure for a particular disease/problem to be investigated facilitate the conduct of such studies

5. Pre-study formal and informal negotiations and discussions with relevant stakeholders to obtain approval is important

6. Keeping stakeholders involved by communicating with them about the study and following up unresolved issues

7. Studies carried out by or on behalf of the relevant regulatory bodies (e.g. Health and Safety Executive "HSE") are easier to get approvals and cooperation from the relevant stakeholders

8. Studies that have been designed to specific gaps in government or other policies are easier to get approvals and cooperation from the relevant stakeholders

9. Data from previous large and well-designed epidemiological studies can be exploited to facilitate current studies

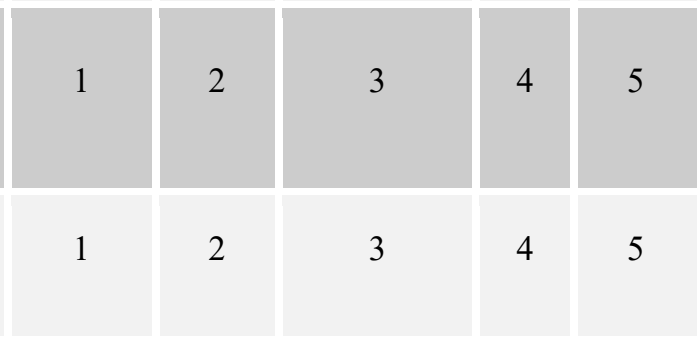

Please state any other things, not mentioned above, you think are facilitators to occupational epidemiology research in the UK. 
g) Which facilitators from the above do you consider are the most important, and why?

h) Have you ever prematurely stopped any of your studies? If yes, why?

i) Have any of your studies been compromised? If yes, why?

j) Have any of your studies been considerably delayed? If yes, why?

k) Have you ever been unable to publish your research findings? If yes, why? 


\section{Demographic and background information}

1. What is your highest level of education?

Undergraduate degree

Master's degree

Doctorate

Other (please indicate)

2. What is your primary work area in occupational epidemiology research?

3. Please choose one that best suits your current role?

Physician

Nurse

Statistician

Epidemiologist

Occupational Hygienist

Other, (please specify)

4. Who is your employer?

University

Governmental body

Research institute/charity

Industry

National Health Service (NHS)

Other, (please specify)

5. For how many years you have been involved in occupational epidemiology research?

6. Please list any other researchers or stakeholders you think they might be interested in completing the questionnaire. 